his presence on the Commission cannot make up for its lack of independent medical men, men free from the habitual trammels of red tape and tradition-tradition founded upon the prevention of idleness and not upon the treatment of disease-a defect which strikes at the root of the Poor-law and renders to a great extent nugatory the elaborate system under which we at present groan.

I cannot but think, Sirs, that if your immense influence and that of your readers were to be exerted for the rectification of such an omission as that which $\mathrm{I}$ have indicated it would not be found too late to do so. As it stands it makes the Royal Commission a very weak one and inflicts a gross injustice amounting to an insult upon the medical profession. I am, Sirs, yours faithfull $v$,

Fellows-road, N.W., Dec. 2nd, 1905. F. R. HUMPHREYS,

PS.-I have already called attention to the matter in one of the daily papers.

\section{"MATERNAL IMPRESSIONS."}

\section{To the Editors of THE LANCET.}

SiRs,-Among the many existent popular beliefs about which there are many fallacies that concerning "maternal impressions" is one of the most common and abiding. That there may be some, if not much, truth in the popular explanation of certain phenomena in this connexion the following cases of interest may show.

A married woman has five children, all boys. The fourth was born 18 months ago with a hare lip and cleft palate. The first operation for its relief took place during his first fortnight and since then seven opera. tions have finally led to complete success, leaving only a linear, slightly raised, scar as evidence of former deformity. When this child was about nine months old and still under treatment his mother again became pregnant and when her fifth son was born two weeks ago ber first question was, "Is its lip marked?" Sure enough it was, not with hare lip or cleft palate but with a linear raised scar extending from the left nostril to the lip, identical with that of his brother. The nother tells me that at the time she became pregnant with her fourth son there were a man and woman in the same village each with hare lip and although she did not fear any evil result to her offspring from seeing them she was "constantly dreaming about them." When the fifth ron was conceived she was very anxious about the elder child who, at the time, had the scar resulting from the carlier operation.

One might say these were cases of reversion or arrested development but this does not explain why arrest of development occurred. The popular idea of the mother's mental affecting the child's physical state seems reasonable in the cases quoted, I think. The important point seems to be the fact of the "impression" occurring at or about the time of conception, for, of course, the possibility of any maternal impression affecting the physical or anatomical condition of a foetus of, say, three or four months would be unthinkable.

Watford, Dec. 3rd, 1905. am, Sirs, yours faithfully

G. Francis SMITH.

\section{A NEW SURGICAL DRESSING-MICA.}

\section{To the Editors of THE LANCET.}

SIRS,-I am greatly interested in the article by Mr. J. L. A. Aymard in your issue of Nov. 18th. I have long advocated the use of glass in dressings but for a totally different reason, not as in Mr. Aymard's case, purely as a non-irritating and convenient dressing, but because I believe sunlight to have a direct and beneficial influence on the healing of wounds. I, however, propose to try a number of cases before further rushing into print on the matter.

Being dissatisfied with glass I am experimenting with mica as a substitute, but as this material is opaque to violet rays, which are those which would be most beneficent in the healing of wounds, its use as a dressing for the treatment of wounds by sunlight is doubtful. For making a window for inspection over the damaged area or for the purposes mentioned by $\mathrm{Mr}$. Aymard, I am of opinion that it is in every way superior to glass; it bends without breaking; it can be used much thinner, consequently it is not so clumsy as glass; it can be fastened over the wound with strapping, and 1 have myself worn a piece strapped on my arm for a considerable time without it breaking or cracking ; it enables one to dispense with a considerable amount of bandaging and is consequently cooler and more comfortable. By enabling the surgeon to inspect the site of injury without disturbing any dressings it is a source of great comfort to the patient and a great convenience to the surgeon, who in satisfactory cuses can leave the first and only dressing on until the wound has healed instead of having frequently to change the dressings purely to ascertain how things are going on under it. I have subjected mica for a period of 24 hours to the following chemicals, \&c., which might come in contact with it during use and I have, been unable to find any change in the mica so used: Dry heat; boiling in water ; carbolic acid lotion, 1 in 20; hydrarg. perchlor., 1 in 100 ; formaldehyde, 40 per cent.; pot. permang.; chinosol, 1 in 250 ; izal ; glycothymolin listerine; hydrogen peroxide; chloroform; and adrenalin Messrs. Down Bros. are obtaining me the mica plates in different sizes. My method is to take three or four layers of gauze or lint, place them over the skin, a hole being cut through the layer of lint to leave the wound exposed; over this a mica plate is placed and the whole is fastened on with some adhesive plaster. These windows cannot be used everywhere or in cases with much discharge but they are possible in a considerable proportion of cases.

I am, Sirs, yours faithfully,

Leytonstone, N.E., Nor. 29tb, $1905 . \quad$ ARTHUR TuDd-White.

\section{SPIROCH无TE PALLIDA AND LEISHMAN- DONOVAN BODIES.}

\section{To the Editors of THE LANCET.}

Sirs,--It is not difficult to demonstrate in syphilitic lesions (at least in primary and secondary eruptions) a spirochæte identical in characters with those described by Schaudinn and Hoffmann, McWeeney, Dudgeon, and others. By fixing in alcohol and staining with Giemsa's or Leishman's mixtures I prepared slides from the fluids expressed from mucous tubercles of a case under Dr. F. J. Paley which showed numbers of these delicate spirillary bodies. If it is true that a spirochrte be a protozoon and a stage in the lifehistory of a trypanosome one mirht find in pseudo-diphtheritic angina, relapsing fever, \&c., the Leishman-Donovan bodies of kala-azar, which is probably a trypanosome disease. In this re-pect and in its possible causal relation to syphilis the presence or absence of these bodies in syphilised man or apes would be of value as evidence. I cannot find any references in available literature of the subject so far. I am. Sirs, jours faithfully,

Brighton, Nor. 29th, 1905. F. G. Bushneli.

\section{ROYAL COLLEGE OF SURGEONS OF ENGLAND.}

\section{To the Editors of THE LANCET.}

SIRS,-In thanking you for your words of support and encouragement to the Members of this College contained in the leading article in your issue of Dec. 2nd, p. 1630, may I venture to suggest that these would be more valuable if published before instead of after the annual meeting? In the old days to which you refer THE LANCET always drew the attention of its readers to the meeting about to be held. This year I do not think there was a single anticipa. tory notice in the medical press.

As honorary secretary of the Society of Members I can fully endorse your statement regarding the principal reason for the poor attendance at these meetings. From letters which I constantly receive I know that many Members are sick of the College and all its works. If they are not wanted there they are more than willing to stay away; they cannot be expected to take any interest in the affairs of a College in which they are steadily denied any representation. The Council persists in regarding those of the Members who do attend as hostile to the interests of the College, than which nothing can be more absurd ; in fact, the Council seems to imagine that it is conferring a favour on the Members by taking any notice of them at all, although they are the legal owners of the College propertiy. While this attitude is maintained is it surprising that the Members, who alter all form the bulk of the profession, take no notice of the Council? 